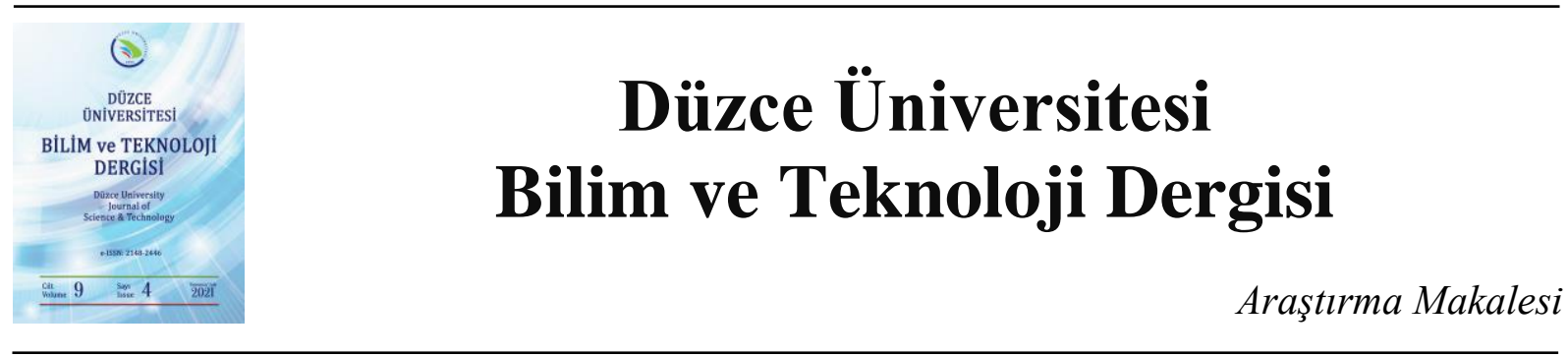

\section{Yüksek Teknoloji İhracatında Türkiye'nin Yeri ve Belirleyicileri}

\author{
(iD) Özlem AKAY a,* \\ ${ }^{a}$ Ístatistik Bölümü, Fen Edebiyat Fakültesi, Çukurova Üniversitesi, Adana, TÜRKIYE \\ * Sorumlu yazarin e-posta adresi: oakay@cu.edu.tr
}

DOI: 10.29130/dubited.861464

\begin{abstract}
$\underline{\mathrm{OZZ}}$
Yüksek teknoloji ihracatı, ülkelerin ekonomik olarak kalkınması ve uluslararası rekabet üstünlüğü sağlayabilmeleri açısından oldukça önemlidir. Özellikle gelişmekte olan ülkelerin ekonomik büyümelerini artırmak için yüksek teknoloji ihracatı üzerinde durulması gereken bir konudur. Dolayısıyla yüksek teknoloji ihracatı ve yüksek teknoloji ihracatını etkileyen faktörlerin ortaya konulması gerekmektedir. Bu nedenle çalışmada, yüksek teknoloji ihracatı açısından Türkiye'nin Avrupa Birliği üyesi ülkeler arasında bulunduğu yerin ve Türkiye'de yüksek teknoloji ihracatını etkileyen faktörlerin önem düzeyinin belirlenmesi amaçlanmaktadır. Bu amaç doğrultusunda, ilk olarak, 2007-2018 yılları arası Avrupa Birliği üyesi ülkelerin ve Türkiye'nin yüksek teknoloji ihracat verileri alınarak zaman serisi kümeleme analizi ile Türkiye'nin Avrupa Birliği ülkeleri arasındaki yeri belirlenmiştir. Daha sonra, yapay sinir ağları kullanılarak Türkiye için yüksek teknoloji ihracatı belirleyicilerinin önem düzeyleri elde edilmiştir.
\end{abstract}

Anahtar Kelimeler: Yüksek teknoloji ihracatı, Kümeleme analizi, Yapay sinir ağları.

\section{Determinants of High Technology Exports and Turkey's state}

\begin{abstract}
High technology exports are very important for countries to develop economically and to gain an international competitive advantage. In order to increase the economic growth of developing countries, it is an issue that needs to be focused on high technology exports. Therefore, it is necessary to reveal the factors affecting high technology exports and high technology exports. Therefore, the study aims to determine the location of Turkey among European Union member countries in terms of the high-tech exports and the importance of the factors affecting the level of high-tech exports in Turkey. First, between the years 2007-2018 the European Union countries and Turkey's high-tech export data were obtained. Turkey's location has been determined among European union countries by performing time series clustering analysis to these data. Then, for Turkey significance level of factors affecting high-tech exports was determined using artificial neural networks.
\end{abstract}

Keywords: High technology export, Cluster analysis, Artificial neural networks.

Geliş: 14/01/2021, Düzeltme: 15/04/2021, Kabul: 23/04/2021 


\section{GIRIS}

Küreselleşme ile birlikte, uluslararası pazarlarda ülkeler arası rekabet seviyesi de artmaktadır [1]. Ülkelerin teknolojik gelişme seviyeleri rekabet düzeyini etkileyen en önemli faktördür [2]. Ülkeler ihracat piyasasındaki paylarını, yeni-yüksek verimli endüstrilerde rekabet yeteneğini başarılı bir şekilde arttırarak korumaktadırlar [3]. Bunula birlikte yüksek teknolojili ürün üretimi ve teknolojik gelişme ülkelerin ekonomik büyümelerinde ve uluslararası ticaretlerinde oldukça önemli bir yer tutmaktadır [4]. Esasen yüksek büyüme potansiyeli bulunan ekonomilerde, rekabet avantajının devamlılığı için ileri teknolojili ürünlerin toplam ihracat içerisinde payları arttırılmalıdır [5].

Teknolojide meydana gelen gelişmeler ve iyileşmeler ile birlikte ekonomide değişimler ve dönüşümler gerçekleşmektedir [6]. Ekonomileri hızlı bir şekilde büyüyen ülkelerin, yüksek teknoloji endüstrilerinde ve teknolojiye dayalı sektörlerde inovasyona yönelme ve tüm ürünlerdeki yüksek teknoloji ürünlerinin payını arttırma gibi hedefleri bulunmaktadır [7]. Gelişmiş ülkelerde uzun dönemde ekonomik büyümenin en önemli faktörlerinden birisi teknolojik gelişmelerdir. Aynı zamanda gelişmekte olan ülkelerin ekonomik büyümesi için yüksek teknoloji ihracatı gereklidir [8].

Yüksek teknoloji üretimi, “yüksek getiri sağlayan ve yüksek katma değerli ürün üretimi” olarak tanımlanmaktadır [6]. Yüksek teknoloji üretimi, üretim sürecindeki teknolojinin yoğunluğuna bağlı olarak üretim faktörlerinin daha etkin kullanılması ile üretimde verimliliği ve kalite artışını sağlamaktadır [9]. Ayrıca, gelir esnekliğinin yüksek olması yüksek teknolojiye sahip malların en önemli özelliğidir [10]. Uluslararası ticaretin en hızlı büyüyen sektörünü yüksek teknoloji yoğun ürün ihracatı oluşturmaktadır. Çoğunlukla gelişmiş ve inovasyon teknolojileri bulunan endüstrilere ve firmalara atfedilmek amacıyla yüksek teknoloji ürünleri veya hizmetleri kullanılmaktadır [11]. Bu bakımdan yüksek teknolojiye sahip ürünler, gelişmekte olan ülkeler tarafından ihraç edilen ürünlerin önemli bir kısmını oluşturmaktadır [12].

Yüksek teknoloji ürün ihracatı üzerine literatürde birçok çalışma bulunmaktadır. Ele alınan çalışmaların bir bölümü, inovasyonun uluslararası ticaret ve ihracat üzerindeki etkisini, diğer bölümü yüksek teknoloji ürün ihracatını etkileyen faktörleri incelemiştir. Bu çalışmalardan bazıları aşağıdaki gibi özetlenmiştir.

Hollenstein (2003) [13] çalışmasında, servislerdeki inovasyon modellerinin anlaşılmasına katkıda bulunmak için inovasyon göstergelerine göre benzer olan firmaları kümeler halinde gruplandırmıştır. İsviçre örneğinde, inovasyonla ilgili çok sayıda faktörü ve çeşitli yapısal özelliği bulunan firmaları beş kümede tanımlamıştır. Kümeler belirli "yenilik modları" olarak yorumlanmış ve bu modların "ekonomik olarak eşdeğer" olup olmadığı araştırılmıştır. Bu durumda benzer firmaların sırasız sınıflandırılması, sektörlerin yenilikçiliklerine göre sıralanmasından daha uygun olmuştur. Lee ve Song (2007) [14] çalışmalarında, stratejik araştırma alanlarını seçmek için "Teknoloji Kümesi Analizi” yöntemi önermişlerdir. Teknoloji kümeleme analizi, temel göstergelere dayalı olarak teknolojileri bir araya getirmektedir. Yöntem, nano teknoloji alanındaki ulusal Ar-Ge programlarına uygulanmıştır. Elli altı nano teknoloji analiz edilmiş ve 180 uzmanın anket verilerine göre üç ana kümeye ayrılmıştır. Bireysel teknolojiler arasındaki teknolojik uzaklıklar ve korelasyonlar hiyerarşik dendrogram ile gösterilmiştir. Nano teknoloji alanında üç ana küme bulunmuş ve nano malzemeler, nano cihazlar ve nano-biyo olarak adlandırılmıştır. Elde edilen üç kümenin, Güney Kore'deki nano teknoloji alanındaki çekirdek teknoloji kümeleri olması beklenmektedir. Chyi ve ark. (2012) [15] çalışmalarında, Hsinchu yüksek teknoloji kümelerinde büyümenin altında yatan mekanizmaları ampirik olarak araştırmışlardır. Bilgi yayılımlarını, yığına fayda sağlayan potansiyel faktörlerden biri olarak vurgulamışlardır. İç ve dış yayılımların Hsinchu yüksek teknoloji kümelerindeki firma performansı üzerindeki etkisi incelenmiştir. Ampirik sonuçlar, dış Ar-Ge yayılımının Hsinchu yüksek teknoloji kümelerindeki firmaların net satışlarını açıklamada istatistiksel olarak önemli olduğuna dair destekleyici kanıtlar sağlamıştır. Göçer (2013) [16] çalışmasında, 1996-2012 yılları arası verileri 
kullanarak gelişmekte olan 11 Asya ülkesi için Ar-Ge harcamalarının bilgi-iletişim teknolojileri ihracatı, toplam ihracat, yüksek teknolojili ürün ihracatı ve ekonomik büyüme üzerindeki etkilerini ve yüksek teknolojili ürün ihracatının dış ticaret dengesi üzerindeki etkilerini panel veri analizi ile belirlemiştir. Hadri-Kuruzomi (2012) [17] panel birim kök testi ile serilerin durağanlığı, DumitrescuHurlin (2012) [18] testi ile nedensellik ilişkisi, Westerlung-Edgerton (2007) [19] LM bootstrap testi ile eşbütünleşme ilişkisi incelenmiştir. Eberhardt-Bond (2009) [20] Panel AMG yöntemi ile katsayılar tahmin edilmiştir. Elde edilen bulgular, Ar-Ge harcamalarındaki \%1'lik artışın yüksek bilgi-iletişim teknolojileri ihracatını $\% 0.6$, teknolojili ürün ihracatını $\% 6.5$ ve ekonomik büyümeyi $\% 0.43$ oranında arttırdığını göstermiştir. Şahbaz ve ark. (2014) [5] çalışmalarında, Türkiye ve 17 AB ülkesi için 19962011 yıllarına ait verileri kullanarak Ar-Ge harcamaları ile ileri teknoloji mal ihracatı arasındaki ilişkiyi panel nedensellik ve panel eşbütünleşme analizleri ile belirlemişlerdir. Analiz sonuçları, Ar-Ge harcamaları ve ileri teknoloji mal ihracatı arasında çift yönlü Granger nedenselliğinin olduğunu göstermiş̧tir. Telatar ve ark. (2016) [21] çalışmalarında, Türkiye'de teknoloji yoğunluklu ürün ihracatının ekonomik büyüme üzerindeki etkisini zaman serisi analizleri ile ortaya koymuşlardır. 1996:01-2015:03 dönemi üçer aylık veriler ele alınmış ve Avrupa Birliği Ekonomik Aktivitelerin İstatistiki Sınıflaması Revizyon 2'ye göre imalat sanayinin teknoloji yoğunlukları üç alt gruba ayrılmıştır. Granger nedensellik ve Engle-Granger (1987) [22] eşbütünleşme testleri ile değişkenler arası ilişkiler incelenmiştir. Analiz sonuçları, düşük ve orta teknolojili ürün ihracatının Türkiye'nin ekonomik büyümesini pozitif etkilediğini göstermiştir. Bunun yanısıra orta ve ileri teknoloji yoğunluklu ürün ihracatından ekonomik büyümeye doğru tek yönlü nedensellik söz konusudur. Kızılkaya ve ark. (2017) [23] çalışmalarında, gelişmekte olan 12 ülke için 2000-2012 yıllarında doğrudan yabancı sermaye yatırımlarının ve dışa açıklığın yüksek teknolojili ürün ihracatı üzerindeki etkisini araştırmışlardır. Elde edilen bulgular, dışa açıklığın ve doğrudan yabancı sermaye yatırımlarının yüksek teknolojili ürün ihracatını pozitif etkilediğini göstermiştir. Konak (2018) [6] yüksek teknoloji içeren ürün ihracatının büyüklügünü, gelişimini ve ekonomik büyüme üzerindeki etkilerini seçilmiş OECD üyesi ülkeler ve Türkiye için incelemiştir. 1992-2016 yıllarına ait Dünya Bankası verilerinden yararlanmıştır. Elde edilen bulgular, Türkiye'nin toplam ihracatı içerisindeki yüksek teknoloji içeren ürün ihracatı payının, 1999-2001 yılları hariç olmak üzere incelen dönem itibariyle \%2 seviyesinden daha aşağı seviyelerde gerçekleştiğini, 1999-2001 alt döneminde bu oranın ancak \%4 seviyesine kadar yükselebildiğini göstermiştir. Türkiye'nin ihracatının ağırlıklı olarak "düşük", "düşük-orta" ve "orta-ileri” teknolojilere dayalı olduğu tespit edilmiş ve Türkiye'nin diğer OECD üyesi ülkelerin oldukça gerisinde bulunduğu belirlenmiştir. Güneş ve Akın (2019) [24] çalışmalarında, Türkiye için 1989-2016 yıllarında yüksek teknolojili ürün ihracatını etkileyen faktörleri VAR modeli kullanarak belirlemişlerdir. Elde edilen bulgulara göre, sanayi sektöründeki katma değer değişkeni istatistiksel olarak anlamlıdır. Yüksek teknolojili ürün ihracatı ikinci dönemde azalarak sanayi sektöründeki katma değer düşüşüne tepki vermiştir. Varyans ayrıştırma analizi sonuçlarına göre, ikinci dönem itibari ile yüksek teknolojili ürün ihracatı gecikmelerinin etkisi azalmaktadır ve diğer değişkenlerin katkısı ortaya çıkmaktadır. Akyol ve Demez (2020) [25] çalışmalarında, yeni endüstrileşen ülkeler grubunu dikkate alarak inovasyonun yüksek teknoloji ürün ihracatı üzerindeki etkisini incelemişlerdir. 1996-2015 dönemini kapsayan yeni endüstrileşen 8 ülke için inovasyon faaliyetlerinin yüksek teknoloji ürün ihracatını pozitif etkilediğini belirlemişlerdir. Erdinç ve Aydınbaş (2020) [7] çalışmalarında, 2007-2018 yıllarına ait verileri kullanarak seçilmiş 16 ülke için yüksek teknoloji ürünlerin ihracatını etkileyen faktörleri panel veri analizi ile incelemişlerdir. Yüksek teknoloji ürünleri ihracatı bağımlı; patent başvuru sayısı, bilim-teknik dergi makale sayısı ve GSYH faktörleri bağımsız değişken olarak ele alınmış ve bu değişkenlerin yüksek teknoloji ürünleri ihracatına etkileri belirlenmiştir.

$\mathrm{Bu}$ çalışmada Avrupa birliği üyesi ülkeler ve Türkiye için yüksek teknoloji ihracatı verileri kullanılarak zaman serileri kümeleme analizi ile Yüksek teknoloji ihracatı açısından Türkiye'nin Avrupa birliği üye ülkeler arasındaki yeri belirlenecektir. Daha sonra Türkiye için yüksek teknoloji ihracatı ve yüksek teknoloji ihracatını etkilediği düşünülen Patent Başvuru Sayısı, Ar-Ge harcamaları, Doğrudan Yabancı Yatırım ve Dışa Açıklık Oranı değişkenleri ele alınarak yapay sinir ağları ile yüksek teknoloji ihracatını etkileyen bu faktörlerin önem düzeyleri elde edilecektir.

Çalışmanın giriş bölümünde kısaca yüksek teknolojili ürün ihracatı ile ilgili bilgiler verilmiş ve çalışma ile ilgili literatür incelenmiştir. İkinci bölümde yöntem tanıtılmış, üçüncü bölümde ise veri seti 
ve ampirik bulgulara yer verilmiştir. Sonuç bölümünde elde edilen bulgular doğrultusunda bazı tespitlerde ve önerilerde bulunulmuştur.

\section{YÖNTEM}

\section{A. ZAMAN SERILERİ KÜMELEME ANALIZİ}

Zaman serisi veri madenciliği, son yıllarda bu tip verilerin yaygınlaşması nedeniyle büyük ilgi görmektedir. Zaman serisi kümeleme özel bir kümeleme türüdür. Statik veri kümeleme gibi, zaman serisi kümeleme, etiketlenmemiş veri elemanları ile kümeleri oluşturmak için bir kümeleme algoritması veya prosedürü gerektirir. Kümeleme algoritmasının seçimi, hem mevcut verilerin türüne hem de belirli amaca ve uygulamaya bağlıdır.

Literatürdeki mevcut çalışmalar gözden geçirildiğinde, zaman serisi kümelemesi boyutsallık azaltma veya temsil yöntemi, uzaklık ölçümü, kümeleme algoritması, prototip tanımlama ve değerlendirme olmak üzere esas olarak dört bileşene sahiptir. Zaman serisi kümeleme algoritmaları veri ve algoritma uyarlaması olarak sınıflandırılabilir. Literatürde, zaman serileri arasında dört kategoriye ayrılmış uzaklık ölçümleri önerilmiştir. Bunlar modelden bağımsız, modele dayalı, karmaşıklığa dayalı ve tahmine dayalı ölçümlerdir.

Çalışmada modelden bağımsız uzaklık ölçümlerinden ham veri tabanlı Dinamik zaman atlama (DTW) uzaklık ölçümü ile otokorelasyon temelli uzaklık ölçümü kullanılarak hiyerarşik ve Partitioning Around Medoids (PAM) yöntemleri ile zaman serisi kümeleme analizi yapılmıştır. Bunun yanısıra Maharaj uzaklık ölçümü kullanılarak modele dayalı zaman serisi kümeleme analizi yapılmıştır.

DTW uzaklığı Sankoff ve Kruskal (1983) [26] tarafindan derinlemesine incelenmiş ve Berndt ve Clifford (1994) [27] tarafından zaman serilerinde örüntüler bulmak için önerilmiştir. Fr'echet uzaklığ1 olarak, DTW uzaklığı, gözlem çiftleri $\left(X_{a i}, Y_{b i}\right)$ arasındaki uzaklık ölçümünü minimum yapmak için seriler arasında bir eşleme $r$ bulmayı amaçlamaktadır. DTW uzaklık ölçümü aşağıdaki gibi verilmiştir.

$d_{D T W}\left(X_{T}, Y_{T}\right)=\min _{r \in M}\left(\sum_{i=1, \ldots, m}\left|X_{a i}-Y_{b i}\right|\right)$

Galeano ve Pẽna (2000) [28], Caiado ve ark. (2006) [29], ve D’Ursoand Maharaj (2009) [30] gibi bazı araştırmacılar tahmini otokorelasyon işlevlerine dayalı ölçümleri değerlendirmişlerdir. $\hat{p}_{i, X_{T}} \approx 0$ ve $\hat{p}_{1, Y_{T}} \approx 0$ için $\mathrm{i}>\mathrm{L}$ için $\hat{p}_{X_{T}}=\left(\hat{p}_{1, X_{T}}, \ldots, \hat{p}_{L, X_{T}}\right)^{T}$ ve $\hat{p}_{Y_{T}}=\left(\hat{p}_{1, Y_{T}}, \ldots, \hat{p}_{L, Y_{T}}\right)^{T}$ bazı L'ler için sirasiyla $X_{T}$ ve $Y_{T}$ 'nin tahmini otokorelasyon vektörleri olmak üzere Galeano ve Pe na (2000) [28] $X_{T}$ ile $\mathrm{Y}_{\mathrm{T}}$ arasındaki uzaklığı aşağıdaki gibi tanımlamaktadır.

$d_{A C F}\left(X_{T}, Y_{T}\right)=\sqrt{\left(\hat{p}_{X_{T}}-\hat{p}_{Y_{T}}\right)^{T} \Omega\left(\hat{p}_{X_{T}}-\hat{p}_{Y_{T}}\right)}$

Burada, $\Omega$ bir ağırlık matrisidir.

Modele dayalı uzaklık ölçümleri, temel modellerin belirli parametrik yapılardan oluşturulduğunu varsayar. Literatürdeki ana yaklaşım, $X_{T}$ ve $Y_{T}$ 'nin üretim süreçlerinin tersinir ARIMA modellerini takip ettiğini varsaymaktır. Böyle bir durumda amaç, her seriye bir ARIMA modeli uydurmak ve daha sonra uydurulan modeller arasındaki uzaklığı ölçmektir. İlk adım, ARIMA modellerinin yapısını ve parametrelerini tahmin etmeyi gerektirir. Yapının ya verildiği varsayılır ya da örneğin, Akaike bilgi kriteri (AIC) veya Schawartz Bayesçi bilgi kriteri (BIC) kullanılarak otomatik olarak tahmin edilir. Parametre değerleri genellikle genelleştirilmiş en küçük kareler tahmin ediciler kullanılarak uydurulur. ARIMA modelleri varsayımı altında literatürde türetilen uzaklık ölçütlerinden Maharaj uzaklığı aşağıda verilmiştir. 
Tersinir ve durağan ARMA süreçleri sınıfı için Maharaj (1996, 2000) [31, 32], iki zaman serisinin önemli ölçüde farklı üretim süreçlerine sahip olup olmadığını belirlemek için hipotez testine dayalı tutarsızlık ölçüsü sunmuştur. Bu ölçüt aşağıdaki test istatistiği ile verilir.

$d_{M A H}\left(X_{T}, Y_{T}\right)=\sqrt{T}\left(\widehat{\Pi}_{X_{T}}^{\prime}-\widehat{\Pi}_{Y_{T}}^{\prime}\right)^{\prime} \widehat{V}^{-1}\left(\widehat{\Pi}_{X_{T}}^{\prime}-\widehat{\Pi}_{Y_{T}}^{\prime}\right)$

burada, $\widehat{\Pi}_{X_{T}}^{\prime}$ ve $\widehat{\Pi}_{Y_{T}}^{\prime}$, sirasiyla $X_{T}$ ve $Y_{T}^{\prime}$ nin $\mathrm{AR}(\mathrm{k})$ parametre tahminleridir; k, Piccolo'nun uzaklığındaki gibi seçilir ve $\widehat{V}, V=\sigma_{X_{T}}^{2} R_{X_{T}}^{-1}(k)+\sigma_{Y_{T}}^{2} R_{Y_{T}}^{-1}(k)$ 'nın tahminidir. $\sigma_{X_{T}}^{2}$ ve $\sigma_{Y_{T}}^{2}, \mathrm{X}_{\mathrm{T}}$ ve $\mathrm{Y}_{\mathrm{T}}$ ile ilişkili beyaz gürültü süreçlerinin varyanslarını gösterir. $R_{X_{T}}$ ve $R_{Y_{T}}$, her iki serinin örnek kovaryans matrislerini belirtir [33].

\section{B. YAPAY SINIIR AĞLARI}

Yapay sinir hücreleri, biyolojik sinir hücreleri gibi aldıkları girdi sinyallerini toplayıp çıktı olarak işleyen bir sistemdir [34]. Yapay sinir hücrelerine birim, düğüm ya da işlemci elemanı da denilmektedir [35]. Sinir hücreleri katmanlar halinde paralel şekilde dizilerek yapay sinir ağlarını oluştururlar. Yapay sinir ağlarında üç katman bulunmaktadır [36]. Çoğunlukla girdi katmanı ilk, çıkış katmanı ise son katmandır ve tektir. Aradaki katman gizli katman veya ara katmandır ve yapay sinir ağlarının yapısına göre bir ya da birden fazla olabilmektedir [37]. Girişler, girdi katmanından alınır ve girdi ile gizli katman arasındaki bağlantı ağırlıkları ile çarpılarak gizli katmana iletilirler. Girişler gizli katmanda bulunan nöronlara gelir, burada toplanır ve gizli ile çıktı katmanı arasındaki bağlantı ağırlıkları ile çarpılıp çıktı katmanına iletilir. Çıktı katmanında bulunan nöronlar gelen girişleri toplar ve uygun çıktıyı üretir [38]. Bağlantıların ağırlık değerleri öğrenme sürecinde belirlenmektedir [39]. Yapay sinir ağı yapısı Şekil 1'de verilmiştir.

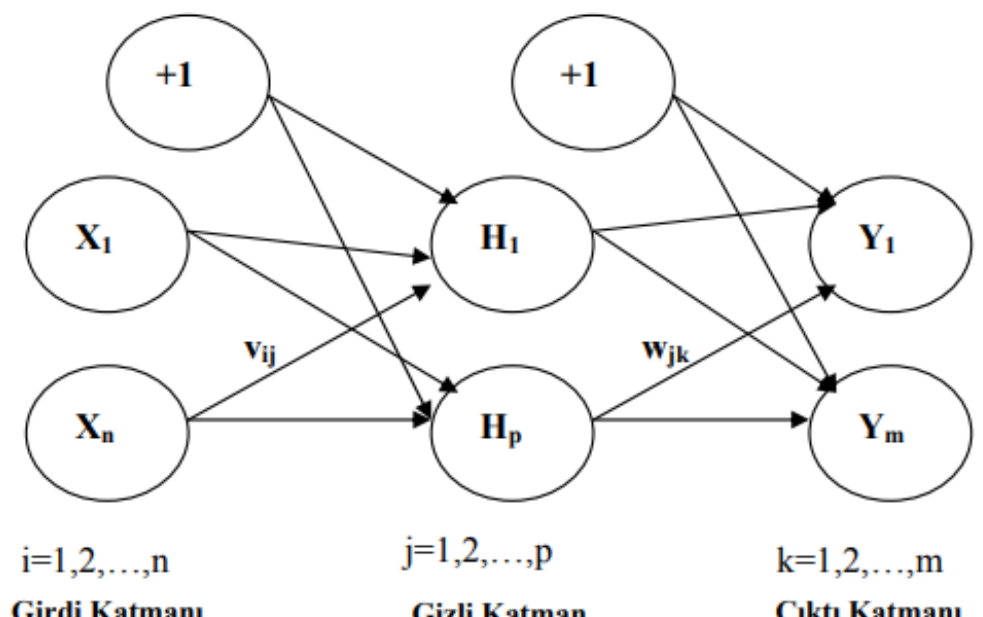

Şekil 1. İleri Beslemeli YSA [40]

Yapay sinir ağları (YSA), işleyiş şekillerine göre ileri ve geri beslemeli ağlar olarak ikiye ayrılır. İleri beslemeli yapay sinir ağlarında sinyaller, girdi katmanından çıktı katmanına doğru tek yönedir. Geri beslemeli ağlarda ise sinyalin yönü girdi katmanından çıktı katmanına doğrudur yani bu ağlarda bir tür geri besleme işlemi vardır [41].

Yapay sinir ağının en önemli özellikleri, farklı problemler için uyarlanabilirliği, paralel dağılmış yapısı, doğrusal olmayan yapıları modelleyebilmesi, hata toleransına sahip olması ile öğrenme ve genelleme yapabilme yeteneğidir [42].

YSA doğrusal olmayan bir model olması ve algoritmalar ile eğitilebilmesi nedeniyle problemlerin çözümünde oldukça başarılıdır. Bunun yanı sıra, deneme yanılma yoluyla uyarlanabilir olması, analiz 
yapmadan önce varsayım şartının olmaması ve veride bilgi kaybı yaşanmamasından dolayı başarısı yüksek modellerdir [43].

\section{AMPIRİK UYGULAMA}

Bir ülkenin teknik olarak gelişmişlik düzeyi o ülkenin teknolojiye yönelik verilerine ve ihracatındaki teknoloji yoğun ürünlerin payına bağlıdır. Bu nedenle çalışma, yüksek teknoloji ihracatı açısından Türkiye'nin Avrupa Birliği üyesi ülkeler arasındaki yerini ve Türkiye'nin yüksek teknoloji ihracatını etkileyen faktörlerinin önem derecesini belirlemeyi amaçlamaktadır. $\mathrm{Bu}$ amaç doğrultusunda ilk olarak, 27 Avrupa birliği üyesi ülke ve Türkiye için 2007-2018 yılları arası yüksek teknoloji ihracat verileri ele alınarak zaman serisi kümeleme analizi yapılmıştır. İkinci aşamada, Türkiye için 20072017 dönemi arası yüksek teknoloji ihracatı oranı, yüksek teknoloji ürün ihracatını etkileyen faktörler olarak literatürde sıklıkla kullanılan Patent Başvuru Sayısı, Ar-Ge harcamaları, Doğrudan Yabancı Yatırım, Dışa Açıklık Oranı, verileri ele alınarak yapay sinir ağları ile bu faktörlerin önem düzeyleri belirlenmiştir. Zaman serisi kümeleme analizi için R, yapay sinir ağı için IBM SPSS Statsitics 22 programı kullanılmıştır. Dışa Açıklık Oranı, Ar-Ge harcamaları ve Doğrudan Yabancı Yatırım değişkenlerinin 2018 yılına ait verileri eksik olduğu için yıl aralığı 2007-2017 olarak alınmıştır. Yüksek teknolojili ürün ihracatının belirleyicileri ile ilgili yapılan çalışmalar ele alındığında; Ar-Ge harcamaları, Ekonomik Büyüme (GSYH), Sabit Sermaye Yatırımı, Patent Başvuru Sayısı, Nitelikli İstihdam Sayıs1, Doğrudan Yabancı Yatırımlar ve Dışa Açıklık Oranı gibi değişkenler olduğu görülmüştür. Yüksek teknolojili ürün ihracatını etkileyen en önemli faktörler arasında ülkelerin yaptıkları Ar-Ge harcamaları ve aldıkları patent sayısı bulunmaktadır. Bununla birlikte DYY'nin ev sahibi ülkeye teknolojik gelişme getirebileceği ve dışa açıklığın yıllar itibariyle artması ile ekonominin yüksek teknolojili ürün ihracatını artırabileceği düşünülmektedir. Yüksek teknoloji ihracatını etkileyen faktörler ülkelere göre farklılık göstermektedir. Çalışmada kullanılan değişkenler ve veri kaynakları Tablo 1'de verilmiştir.

Tablo 1. Analizde Kullanılan Değişkenlere İlişkin Açıklamalar

\begin{tabular}{llll}
\hline Değişkenler & Açıklamas1 & Birim & Kaynak \\
\hline LnYTI & $\begin{array}{l}\text { Logaritmik Yüksek Teknolojili } \\
\text { Urün İhracatı }\end{array}$ & Oran & $\begin{array}{l}\text { EUROSTAT } \\
\text { (https://ec.europa.eu/eurostat/) [44] }\end{array}$ \\
\hline LnArGe & Logaritmik Ar-Ge harcamaları & Oran & $\begin{array}{l}\text { Dünya Bankas1 } \\
\text { (databank.worldbank.org) [45] }\end{array}$ \\
\hline LnPT & $\begin{array}{l}\text { Logaritmik Patent Başvuru } \\
\text { Say1s1 }\end{array}$ & Değer & $\begin{array}{l}\text { Dünya Bankas1 } \\
\text { (databank.worldbank.org) [46] }\end{array}$ \\
\hline LnDA & Logaritmik Dışa Açıklık Oran1 & Oran & $\begin{array}{l}\text { The Global Economy } \\
\text { (www.theglobaleconomy.com) [47] }\end{array}$ \\
\hline LnDYY & $\begin{array}{l}\text { Logaritmik Doğrudan Yabanc1 } \\
\text { Yatırım }\end{array}$ & Değer & $\begin{array}{l}\text { The Global Economy } \\
\text { (www.theglobaleconomy.com) [48] }\end{array}$ \\
\hline
\end{tabular}

28 ülkenin 2007-2018 yılları arası yüksek teknoloji ihracat verilerine modelden bağımsız hiyerarşik ve PAM ile modele dayalı olmak üzere üç farklı yöntemle kümeleme analizi uygulanmıştır. Hiyerarşik ve PAM yöntemlerinde DTW ve ACF olmak üzere 2 farklı uzaklık ölçümü kullanılmıştır. Uygun küme sayısını belirlemek amacıyla 2-7 küme sayıları için kullanılan uzaklık ölçümleri ile yapılan hiyerarşik ve PAM yöntemlerine ait küme geçerlilik indekslerinden Dunn, Connectivity ve Silhouette değerleri hesaplanmıştır. Bulunan değerler Tablo 2 ve Tablo 3'te verilmiştir. 
Tablo 2. DTW ve ACF uzaklık yöntemleri kullanılarak yapılan hiyerarşik kümeleme analizi için küme geçerlilik indeks değerleri

\begin{tabular}{lllllll}
\hline \multicolumn{6}{l}{ Hiyerarşik Kümeleme } \\
\hline \multirow{2}{*}{ Küme say1s1 } & DTW uzaklı̆̆ & ACF uzaklı̆̆ & & \\
& Dunn & Connectivity & Silhouette & Dunn & Connectivity & Silhouette \\
3 & 0.1081174 & 7.627778 & 0.62 & 0.406327 & 6.149206 & 0.49 \\
4 & 0.1535318 & 13.37857 & 0.53 & 0.3268684 & 17.61548 & 0.31 \\
5 & 0.1836592 & 17.70357 & 0.5 & 0.3302836 & 19.92659 & 0.26 \\
6 & 0.2062745 & 19.39524 & 0.48 & 0.3609682 & 24.21349 & 0.30 \\
7 & 0.1535714 & 26.83968 & 0.39 & 0.3677008 & 26.88016 & 0.27 \\
\hline
\end{tabular}

Tablo 3. DTW ve ACF uzaklık yöntemleri kullanılarak yapılan PAM kümeleme analizi için küme geçerlilik indeks değerleri

\begin{tabular}{lllllll}
\hline & \multicolumn{6}{c}{ PAM Kümeleme } \\
\hline \multirow{2}{*}{ Küme say1S1 } & DTW uzaklığ1 & ACF uzaklığ1 & \\
\hline 2 & 0.0988228 & 6.344841 & 0.59 & 0.5169409 & 5.280952 & 0.49 \\
3 & 0.18365 & 12.89841 & 0.58 & 0.2674165 & 18.91825 & 0.28 \\
4 & 0.08615819 & 19.18016 & 0.51 & 0.2872566 & 19.85675 & 0.33 \\
5 & 0.08615819 & 27.37302 & 0.42 & 0.2952859 & 25.51706 & 0.30 \\
6 & 0.08615819 & 28.37302 & 0.39 & 0.2952859 & 26.83651 & 0.29 \\
7 & 0.1746193 & 29.02143 & 0.39 & 0.2952859 & 30.26984 & 0.24 \\
\hline
\end{tabular}

Tablo 2 incelendiğinde DTW uzaklık ölçümü kullanılarak yapılan hiyerarşik kümeleme yöntemi için küme sayısı, Dunn geçerlilik indeks değerine göre (0.2062) 5 küme, Connectivity ve Silhouette indeks değerlerine göre (sırasıyla 7.62, 0.62) 2 küme olarak önerilmektedir. ACF uzaklığı kullanılarak yapılan hiyerarşik kümeleme yöntemi için küme sayısı, Dunn geçerlilik indeks değerine göre (0.412) 7 küme, Connectivity ve Silhouette indeks değerlerine göre (sirasiyla 6.14, 0.49) 2 küme olarak önerilmektedir.

Tablo 3'e bakıldığında DTW uzaklık ölçümü kullanılarak yapılan PAM kümeleme yöntemi için küme sayıs1, Dunn geçerlilik indeks değerine göre (0.18365) 3 küme, Connectivity ve Silhouette indeks değerlerine göre de (sırasıyla 6.34, 0.59) 2 küme olarak önerilmektedir. ACF uzaklığı kullanılarak yapılan PAM kümeleme yöntemi için küme sayıs1, üç indeks değerine göre $(0.516,5.28,0.49) 2$ küme olarak önerilmektedir.

Dunn ve Silhouette indeksleri için maksimum değer, Connectivity indeksi için ise minimum değer uygun küme sayısını göstermektedir. Maharaj uzaklık ölçümü kullanılarak modele dayalı zaman serisi kümeleme ile ise ülkeler 7 kümeye ayrılmıştır. Bu durumda uzaklık ölçümleri kullanılarak hiyerarşik, PAM yöntemleri ve modele dayalı yöntemle yapılan kümeleme analizi ile ülkelerin bulundukları kümeler Tablo 4'te verilmiştir. 
Tablo 4. Kullanılan yöntemler için küme sayılarına göre ülkelerin bulundukları kümeler

\begin{tabular}{|c|c|c|c|c|c|c|c|c|}
\hline & \multicolumn{4}{|c|}{ Hiyerarşik Kümeleme } & \multicolumn{3}{|c|}{ PAM Kümeleme } & \multirow{3}{*}{$\begin{array}{l}\begin{array}{l}\text { Modele } \\
\text { dayalı } \\
\text { kümeleme }\end{array} \\
\begin{array}{l}\text { Küme } \\
\text { sayıs1 } 7\end{array}\end{array}$} \\
\hline & \multicolumn{2}{|c|}{$\begin{array}{l}\text { DTW } \\
\text { uzaklığ } 1\end{array}$} & \multicolumn{2}{|c|}{$\begin{array}{l}\mathrm{ACF} \\
\text { uzaklığ1 }\end{array}$} & \multicolumn{2}{|c|}{$\begin{array}{l}\text { DTW } \\
\text { uzaklığ1 }\end{array}$} & \multirow{2}{*}{$\begin{array}{l}\text { ACF } \\
\text { uzaklığ1 } \\
\text { Küme } \\
\text { sayıs1 } 2\end{array}$} & \\
\hline & $\begin{array}{l}\text { Küme } \\
\text { sayısı } \\
2\end{array}$ & $\begin{array}{l}\text { Küme } \\
\text { sayıs1 } \\
5\end{array}$ & $\begin{array}{l}\text { Küme } \\
\text { sayısı } \\
2\end{array}$ & $\begin{array}{l}\text { Küme } \\
\text { sayısı } \\
7\end{array}$ & $\begin{array}{l}\text { Küme } \\
\text { sayısı } \\
2\end{array}$ & $\begin{array}{l}\text { Küme } \\
\text { sayısı } \\
3\end{array}$ & & \\
\hline Belçika & 1 & 1 & 1 & 1 & 1 & 1 & 1 & 1 \\
\hline Bulgaristan & 1 & 1 & 1 & 2 & 1 & 1 & 1 & 3 \\
\hline Çekya & 1 & 2 & 2 & 3 & 2 & 2 & 2 & 3 \\
\hline Danimarka & 1 & 2 & 2 & 3 & 1 & 1 & 2 & 1 \\
\hline Almanya & 1 & 2 & 1 & 1 & 2 & 2 & 1 & 3 \\
\hline Estonya & 1 & 2 & 1 & 4 & 2 & 2 & 1 & 5 \\
\hline İrlanda & 2 & 3 & 1 & 4 & 2 & 3 & 1 & 1 \\
\hline Yunanistan & 1 & 1 & 2 & 3 & 1 & 1 & 2 & 1 \\
\hline İspanya & 1 & 1 & 1 & 1 & 1 & 1 & 1 & 1 \\
\hline Fransa & 2 & 4 & 1 & 1 & 2 & 2 & 1 & 1 \\
\hline Hirvatistan & 1 & 1 & 1 & 2 & 1 & 1 & 1 & 1 \\
\hline İtalya & 1 & 1 & 1 & 2 & 1 & 1 & 1 & 2 \\
\hline Kibris & 1 & 2 & 1 & 1 & 2 & 2 & 1 & 1 \\
\hline Letonya & 1 & 1 & 1 & 1 & 1 & 1 & 1 & 2 \\
\hline Litvanya & 1 & 1 & 1 & 4 & 1 & 1 & 1 & 6 \\
\hline Lüksemburg & 2 & 5 & 1 & 1 & 2 & 3 & 1 & 3 \\
\hline Macaristan & 2 & 4 & 1 & 1 & 2 & 2 & 1 & 1 \\
\hline Malta & 2 & 3 & 1 & 1 & 2 & 3 & 1 & 1 \\
\hline Hollanda & 2 & 4 & 1 & 1 & 2 & 2 & 1 & 7 \\
\hline Avusturya & 1 & 2 & 1 & 1 & 2 & 2 & 1 & 7 \\
\hline Polonya & 1 & 1 & 1 & 1 & 1 & 1 & 1 & 3 \\
\hline Portekiz & 1 & 1 & 1 & 5 & 1 & 1 & 2 & 1 \\
\hline Romanya & 1 & 1 & 2 & 6 & 1 & 1 & 2 & 1 \\
\hline Slovenya & 1 & 1 & 1 & 2 & 1 & 1 & 1 & 1 \\
\hline Slovakya & 1 & 1 & 1 & 1 & 1 & 1 & 1 & 3 \\
\hline Finlandiya & 1 & 2 & 1 & 1 & 1 & 1 & 1 & 4 \\
\hline İsveç & 1 & 2 & 1 & 7 & 2 & 2 & 1 & 2 \\
\hline Türkiye & 1 & 1 & 1 & 2 & 1 & 1 & 1 & 3 \\
\hline
\end{tabular}

Geçerlilik indekslerine göre, küme sayısı genel olarak 2 küme olarak önerilmektedir. Bununla birlikte Tablo 4'te 2 kümeye ayrılan ülkeler incelendiğinde ülkelerin kümelerde bulunma durumları faklıdır. Ancak ACF uzaklığı kullanılarak yapılan hiyerarşik ve PAM yöntemleri ile 2 kümeye ayrılan ülkeler Portekiz hariç aynı kümelerde bulunmaktadır. Genel olarak bakıldığında Türkiye ve Portekiz aynı kümede yer aldıklarından uygun yöntemin ACF uzaklık ölçümü kullanılarak yapılan hiyerarşik kümeleme yöntemi olduğu görülmektedir. Bu durumda birinci kümedeki ülkeler Avusturya, Belçika, Bulgaristan, Kıbrıs, Fransa, Estonya, Almanya, Finlandiya, İrlanda, Macaristan, Letonya, İtalya, Lüksemburg, Litvanya, Hollanda, Malta, Portekiz, Polonya, Slovakya, İspanya, Slovenya, İsveç, Hirvatistan ve Türkiye'dir. İkinci kümede ise Çekya, Danimarka, Yunanistan, Romanya bulunmaktadır. Şekil 2'de ACF uzaklık ölçümü kullanılarak yapılan hiyerarşik kümeleme yöntemi ile elde edilen dendogram verilmiştir. 


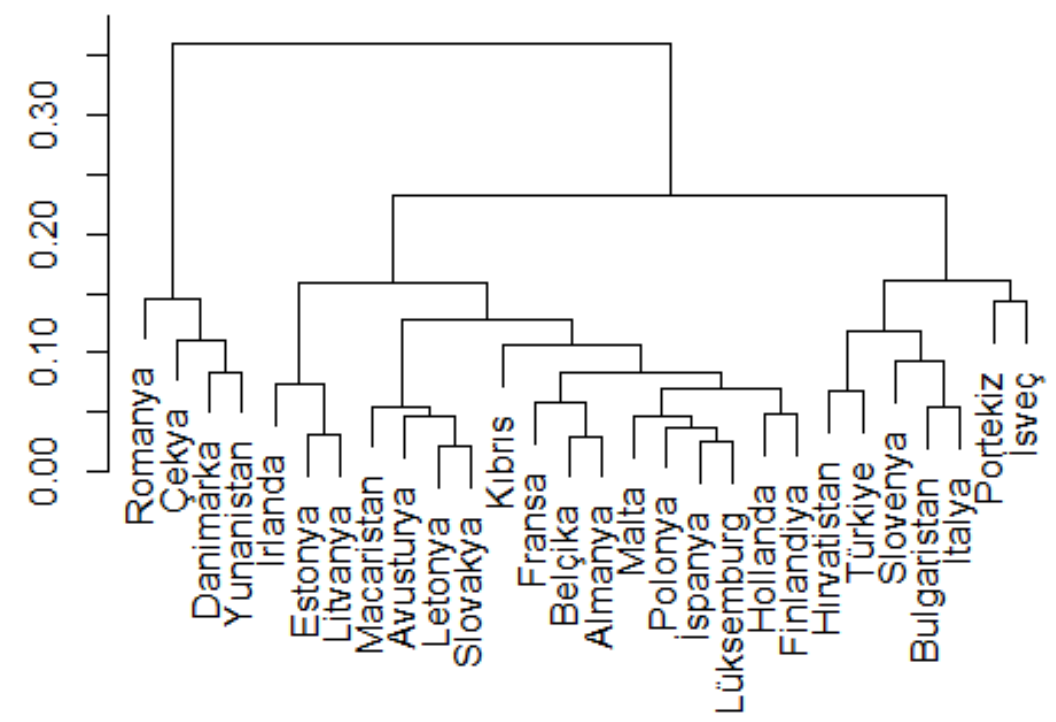

Şekil 2. ACF uzaklık ölçümü kullanılarak yapılan hiyerarşik kümeleme yöntemi ile elde edilen dendogram

Şekil 2'den de açıkça görüldüğü gibi Türkiye, 4 Avrupa Birliği üyesi (Romanya, Çekya, Danimarka ve Yunanistan) hariç diğer Avrupa Birliği ülkeleri ile yüksek teknoloji ihracatı açısından benzerlik göstermektedir.

Birçok probleme yapay sinir ağları ile çözüm bulunabilmektedir. Farklı ağ yapıları kullanılarak problemin tipine uygun olan ağ yapısı araştırmacı tarafından belirlenir [49]. Bu çalışmada Çok Katmanlı Algılayıcı Modeli (ÇKA) kullanılmıştır. Çalışmada kullanılan yapay sinir ağı modeli Şekil 3 ’te verilmiştir. Burada çizgiler ağırlıkları, daireler ise nöronları göstermektedir.

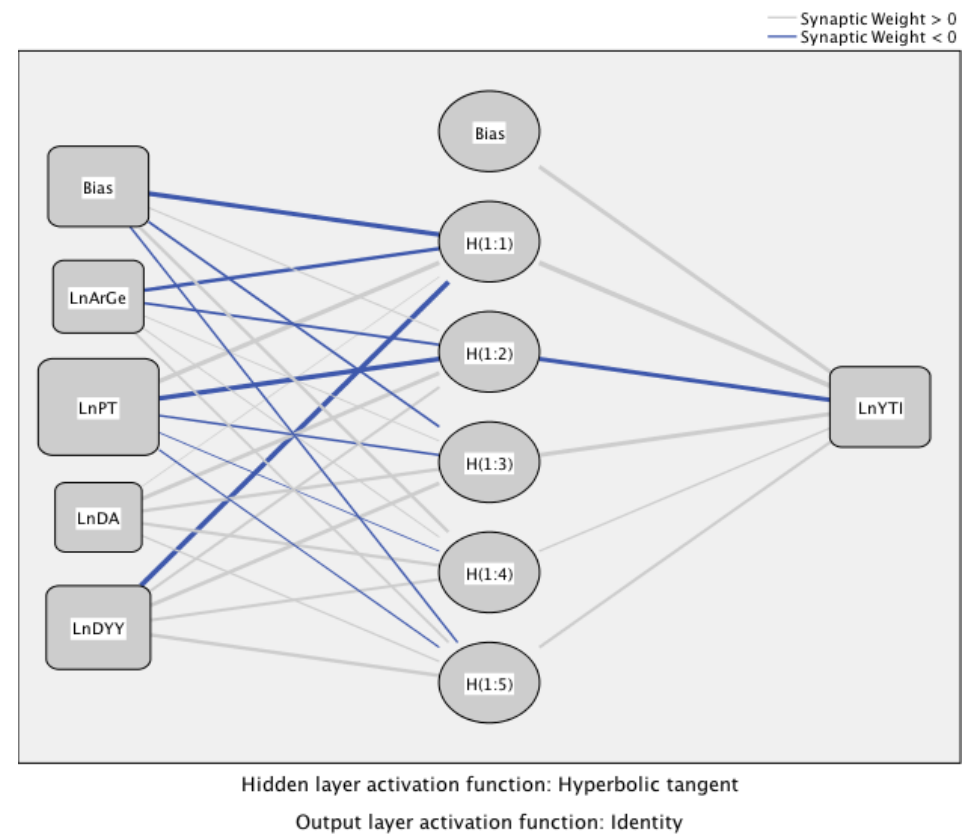

Şekil 3. Çalışmada kullanılan yüksek teknoloji ihracatı için yapay sinir ă̆ı modeli

Modelde birer adet girdi katmanı, gizli katman ve çıkış katmanı yer almaktadır. Dört nöron girdi katmanında, beş nöron gizli katmanda ve bir nöron çıkış katmanında bulunmaktadır. Girdi katmanındaki nöronlar Ar-Ge harcamaları (LnArGe), Patent Başvuru Sayısı (LnPT), Dışa Açıklık Oranı (LnDA), Doğrudan Yabancı Yatırım (LnDYY) bağımsız değişkenleri iken çıktı katmanındaki nöron ise Yüksek teknoloji ihracatı (LnYTI) bağımlı değişkenidir. Verinin \%72.7'si eğitim, \%27.3'ü 
de test verisi olarak kullanılmıştır. Gizli katmanda hiperbolik tanjant fonksiyonu çıktı katmanında ise kimlik doğrulama fonksiyonu kullanılmıştır. Değişkenlerin yeniden ölçeklenme tekniği standardizedir.

Tablo 3.Bă̆ımsız Değişkenlerin Önem Sıralamasına Ait Analiz Sonuçları Tablosu

\begin{tabular}{lll}
\hline Değişkenler & Önem & $\begin{array}{l}\text { Normalleştirilmiş } \\
\text { Düzeyi }\end{array}$ \\
& 0.126 & $\% 25.3$ \\
LnArGe & 0.499 & $\% 100.0$ \\
LnPT & 0.078 & $\% 15.6$ \\
LnDA & 0.297 & $\% 59.5$ \\
LnDYY &
\end{tabular}

Tablo 3'te YSA'da girdi katmanının çıktı katmanı üzerindeki önem düzeyi sıralaması görülmektedir. Burada tüm koşullar değişmese dahi YSA modelinde ilk ağırlıkların tesadüfî olarak atanması nedeniyle sonuçlar az da olsa farklı çıkmakta ve bağımsız değişkenlerin önem sıralaması değişmektedir. Tablo 3'te görüldüğü gibi Patent Başvuru Sayısının (LnPT) yüksek teknoloji ihracatı (LnYTI) üzerine olan etkisi \%100 olarak birinci sırada önem düzeyine sahiptir. \%59.5 değeriyle Doğrudan Yabancı Yatırımın (LnDYY) yüksek teknoloji ihracatı (LnYTI) üzerine olan etkisi ikinci sırada öneme sahipken, \%25.3 Ar-Ge harcamaları (LnArGe), üçüncü sırada önem düzeyine sahiptir. Son sırada ise \%15.6 değeri ile Dışa Açıklık Oranı (LnDA) değişkeni bulunmaktadır. YSA'daki bağlantı ağırlıkları henüz yorumlanamadığından bulunan sonuçlarda modelin kapalı bir kutu olarak kaldığı göz önünde bulundurulmalıdır.

\section{IV.SONUC}

Teknoloji sürekli gelişerek yaşamın her alanında vazgeçilmez bir yer edinmekte ve belirleyici bir rol oynamaktadır. Bilgiye dayalı değişim ile birlikte teknolojiyi üretmek ve yönlendirmek bir "bilimteknoloji” dalına dönüşmektedir. Ülkelerin çoğu bu sürece dahil olmaktadır. Bu nedenle sermaye yoğunluklu teknolojik ilerleme ön plana çıkmaktadır [50, 51].

Yüksek teknoloji, endüstrilerin ve şirketlerin üretim sürecinde teknolojik yeniliklerden ve altyapıdan çok fazla yararlanmaları olarak tanımlanabilmektedir [24]. İç ve dış piyasada verimliliği artırıp ülkelerin büyümesine ve kalkınmasına yönelik bir adım atması ve küresel rekabette güçlenmesi için teknolojiyi etkin olarak kullanmak oldukça önemlidir [23]. Bu nedenle yüksek teknoloji içeren ürünler ve bunların ihracı ülke ekonomilerinin büyümesi ve gelişmesini olumlu bir şekilde etkilemektedir [7]. Bu çalışmada, yüksek teknoloji ihracatı açısından Türkiye'nin Avrupa Birliği üyesi ülkeler arasındaki yeri belirlenmiş ve Türkiye'nin yüksek teknoloji ihracatını etkileyen faktörlerinin önem derecesi elde edilmiştir. Çalışmada ilk olarak, 27 Avrupa birliği üyesi ülke ve Türkiye için 2007-2018 yılları arası yüksek teknoloji ihracat verileri ele alınmıştır. Elde edilen verilere modelden bağımsız hiyerarşik ve PAM ile modele dayalı olmak üzere üç farklı yöntemle zaman serisi kümeleme analizi uygulanmıştır. Hiyerarşik ve PAM yöntemlerinde DTW ve ACF olmak üzere 2 farklı uzaklık ölçümü kullanılmıştır. Kullanılan uzaklık ölçümleri ile yapılan hiyerarşik ve PAM yöntemlerine ait küme geçerlilik indekslerinden Dunn, Connectivity ve Silhouette değerleri 2-7 küme sayısı için hesaplanmıştır. Geçerlilik indekslerine göre, küme sayısı 2 olarak belirlenmiştir. Buna göre, birinci kümedeki ülkeler Avusturya, Belçika, Bulgaristan, Kıbrıs, Fransa, Estonya, Almanya, Finlandiya, İrlanda, Macaristan, Letonya, İtalya, Lüksemburg, Litvanya, Hollanda, Malta, Portekiz, Polonya, Slovakya, İspanya, Slovenya, İsveç, Hırvatistan ve Türkiye'dir. İkinci kümede ise Çekya, Danimarka, Yunanistan, ve Romanya bulunmaktadır. Türkiye ileri teknoloji ihracatı bakımından çoğu Avrupa birliği üyesi ülke ile benzerlik göstermektedir. İkinci aşamada, Türkiye'nin yüksek teknoloji ihracatını etkileyen faktörlerin önem düzeyini belirlemek için 2007-2017 dönemi arası yüksek teknoloji ihracatı oranı, yüksek 
teknoloji ürün ihracatını etkileyen faktörler olarak literatürde sıklıkla kullanılan Patent Başvuru Sayısı, Ar-Ge harcamaları, Doğrudan Yabancı Yatırım ve Dışa Açıklık Oranı verileri ele alınarak yapay sinir ağları ile bu faktörlerin önem düzeyleri belirlenmiştir. YSA ile elde edilen sonuçlara göre, Patent Başvuru Sayısının (LnPT) yüksek teknoloji ihracatı (LnYTI) üzerine olan etkisi \%100 olarak birinci sırada önem düzeyine sahiptir. \%59.5 değeriyle Doğrudan Yabancı Yatırımın (LnDYY) yüksek teknoloji ihracatı (LnYTI) üzerine olan etkisi ikinci sırada öneme sahipken, \%25.3 Ar-Ge harcamaları (LnArGe), üçüncü sırada önem düzeyine sahiptir. Son sırada ise \%15.6 değeri ile Dışa Açıklık Oranı (LnDA) değişkeni bulunmaktadır.

Elde edilen sonuçlardan Türkiye'de yüksek teknoloji ihracatında en etkili değişkenin patent sayıları olduğu görülmektedir. Patent sayısının artması yeni ürün sayısının artması demektir. Bu durum yeni teknolojilerin üretildiğini ve teknolojinin geliştiğini göstermektedir [6]. Türkiye'nin teknolojik altyapısı geliştirilip ürün çeşitliliği yükseltilerek teknolojik gelişme seviyesi ve yüksek teknolojili ürün ihracatı arttırılabilecektir [1]. Türkiye'de doğrudan yabancı yatırımlar imalat sanayinde ileri teknoloji ihracatını artırmaktadır [52]. Ayrıca yeni teknolojilerin ülkeye kazandırılmasında da oldukça etkindir. $\mathrm{Bu}$ nedenle doğrudan sermaye yatırımlarını teşvik edici politikaların uygulanması ve teknoloji yoğun üretim yapmak isteyen yabancı firmalara ek teşvikler sağlanması yüksek teknoloji ihracatını artıracaktır. Böylece ülkenin ekonomik büyümesine de katkı sağlanmış olacaktır. Türkiye'nin yüksek teknoloji ürün ihracatını artırabilmesi için beşeri sermayeye yönelik yatırımlarının artırılarak Ar-Ge faaliyetlerine ve bilim-teknik çalışmalarına daha fazla önem verebilmesi sağlanmalıdır. Ayrıca teknoloji transferi yoluyla ülkeye getirilen teknolojinin Ar-Ge destekli geliştirilmesi ve gerekli teşvik sisteminin oluşturulması da gerekmektedir [53].

Çalışma sonuçları politika yapıcılar açısından önemli çıkarımlar içermektedir. Türkiye'nin yüksek teknoloji ihracatında önemli ilerleme kaydedebilmesi, dünyada yakalanan teknolojik gelişim seviyesini yakından takip etmesi, bilim teknoloji alanında çalışan araştırmacılara mali destek sağlaması, yasal düzenlemelerle teknolojiye teşvik etmesi ve bu konulara yönelik politikalar geliştirmesi ile sağlanabilecektir [7].

TEȘEKKÜR: $\mathrm{Bu}$ çalışma Çukurova Üniversitesi Bilimsel Araştırma Projeleri tarafindan desteklenmiştir (Proje no: 2020-12725).

\section{KAYNAKLAR}

[1] A. Şeker, "Teknolojik Gelişme ve Yüksek Teknoloji İhracatının Ekonomik Karmaşıklık Endeksi Üzerindeki Etkisi: Türkiye Örneği," Yönetim ve Ekonomi: Celal Bayar Üniversitesi İktisadi ve İdari Bilimler Fakültesi Dergisi, c. 26, s. 2, ss. 377-395, 2019.

[2] E. Tekin, ve Y. Hancıŏlu, "İnovasyon Belirleyicilerinin İhracat Performansına Etkisi Üzerine Bir Araştırma," Uluslararası Yönetim İktisat ve İsletme Dergisi, c. 14, s. 4, ss. 897-917, 2018.

[3] T.S. Sara, F.H. Jackson, ve L.T Upchurch, "Role of Innovation in Hi-Tech- Exports of a Nation”, International Journal of Business and Management, c.7, s. 7, ss. 85-93, 2012.

[4] İ. Çütçü, "İnovasyonun İhracat Performansına Etkisi: Yatay-Kesit Analizi Uygulaması," Uluslararası Sosyal Araştırmalar Dergisi, c. 10 s. 48, ss. 586-596, 2017.

[5] A. Şahbaz, R. Yanar, U. Adıgüzel, “Ar-Ge Harcamaları ve İleri Teknoloji Mal İhracatı İlişkisi: 
Panel Nedensellik Analizi,” Ç.Ü. Sosyal Bilimler Enstitüsü Dergisi, c. 23, s. 1, ss. 47-60, 2014.

[6] A. Konak, "Yüksek Teknoloji İçeren Ürün İhracatının İhracat Hacmi ve Ekonomik Büyüme Üzerine Etkisi; Seçilmiş OECD Ülkeleri ve Türkiye Örneği," JOMELIPS-Journal of Management Economics Literature Islamic and Political Sciences, c. 3, s. 2, ss. 56-80, 2018.

[7] Z. Erdinç, ve A. Gökçen, "Yüksek Teknoloji Ürünleri İhracı Ve Belirleyicileri: Panel Veri Analizi", International Social Mentality and Researcher Thinkers Journal, (Issn:2630-631X), c. 6, s. 30, ss. 496-507, 2020.

[8] F. Kula, "Uluslararası sermaye hareketlerinin etkinliği: Türkiye üzerine gözlemler," Cumhuriyet Üniversitesi İktisadi ve İdari Bilimler Dergisi, c. 4, s. 2, 141-154, 2003.

[9] G. Özkan, ve H. Yılmaz, "AR-GE Harcamalarının Yüksek Teknoloji Ürün İhracatı ve Kişi Baş1 Gelir Üzerindeki Etkileri: 12 AB Ülkesi ve Türkiye için Uygulama (1996-2015),” Bilgi Ekonomisi ve Yönetimi Dergisi, c. 12, s. 1, 1-12, 2017.

[10] U. Buzdağl1, A.M. Uzun, S. Ö. Emsen, "yükselen ekonomilerde yüksek teknolojili mal ihracatının belirleyicileri”, Cumhuriyet Üniversitesi İktisadi ve İdari Bilimler Dergisi , c. 20, s. 1, ss. $474-487,2019$.

[11] S. Belay, "Determinants of levels of high technology exports: An empirical investigation", Advances in Competitiveness Research, c. 13, s. 1,ss. 64-79, 2005.

[12] M. Srholec, "High-Tech Exports from Developing Countries: A Symptom of Technology Spurts or Statistical Illusion?" Review of World Economics/WeltwirtschaftlichesArchiv, c. 143, s. 2, ss. 227-255, 2007.

[13] H. Hollenstein, "Innovation modes in the Swiss service sector: a cluster analysis based on firm-level data", Research policy, c. 32, s. 5, ss. 845-863, 2003.

[14] Y. G., Lee, ve Y. I . Song, "Selecting the key research areas in nano-technology field using technology cluster analysis: A case study based on National R\&D Programs in South Korea", Technovation, c. 27, s. (1-2), ss. 57-64, 2007.

[15] Y. L., Chyi, Y. M. Lai ve W. H. Liu, "Knowledge spillovers and firm performance in the hightechnology industrial cluster", Research Policy, c. 41, s. 3, ss. 556-564, 2012.

[16] İ. Göçer, "Ar-Ge harcamalarının yüksek teknolojili ürün ihracatı, dış ticaret dengesi ve ekonomik büyüme üzerindeki etkileri”, Maliye Dergisi, c. 165, s. 2, ss. 215-240, 2013.

[17] K. Hadri, ve E. Kurozumi, "A Simple Panel Stationarity Test in the Presence of Serial Correlation and a Common Factor", Economics Letters, c.115, ss. 31-34, 2012.

[18] E.I. Dumitrescu, ve C. Hurlin, "Testing for Granger Non-Causality in Heterogeneous Panels", Economic Modelling, c. 29, s. 4, ss. 1450-1460, 2012.

[19] J. Westerlund, ve D.L. Edgerton, "A Panel Bootstrap Cointegration Test”, Economic Letters, c. 97 , s. 3, ss. $185-190,2007$.

[20] M. Eberhardt, ve S. Bond, "Cross-section Dependence in Nonstationary Panel Models: A Novel Estimator”, MPRA Paper, No. 17870, 2009. 
[21] O. M. Telatar, M. K., Değer, ve M. A. Doğanay, "Teknoloji yoğunluklu ürün ihracatının ekonomik büyümeye etkisi: Türkiye örneği (1996: Q1-2015: Q3)”, Atatürk Üniversitesi İktisadi ve İdari Bilimler Dergisi, c. 30, s. 4, 2016.

[22] R. F. Engle, ve C.W. J. Granger, "Cointegration and Error Correction: Representation, Estimation and Testing", Econometrica, c. 55 s. 2, ss. 251- 276, 1987.

[23] O. Kızılkaya, E. Sofuoğlu ve A. Ay, "Yüksek teknolojili ürün ihracatı üzerinde doğrudan yabancı sermaye yatırımları ve dışa açıklığın etkisi: Gelişmekte olan ülkelerde panel veri analizi," Doğuş Üniversitesi Dergisi, c. 18, s. 1, ss. 63-78, 2017.

[24] S. Güneş, ve T. Akın, "Yüksek teknolojili ürün ihracatı: Lider ülkeler ve Türkiye analizi”, Sosyoekonomi, c.27 s. 40,ss. 11-29, 2019.

[25] M., Akyol ve S. Demez, "İnovasyonun Yüksek Teknoloji Ürün İhracati Üzerindeki Etkisi: Yeni Endüstrileşen Ülkeler İçin Panel Veri Analizi”, Journal of Yaşar University, c. 15, s. 57, ss. 56$62,2020$.

[26] D. Sankoff ve JB Kruskal, Ed. Time Warps, String Edits, and Macromolecules: The Theory and Practice of Sequence Comparison. Ontario: Addison Wesley Publishing, 1983.

[27] D.J. Berndt, J. Clifford "Using Dynamic Time Warping to Find Patterns in Time Series." In KDD Workshop, ss. 359-370, 1994.

[28] P. Galeano, D. Pe na, "Multivariate Analysis in Vector Time Series", Resenhas do Instituto de Matem'atica e Estat' 'stica da Universidade de S̃ao Paulo, c. 4, s. 4, ss. 383-403, 2000.

[29] J. Caiado, N. Crato, D. Pẽna, "A Periodogram-Based Metric for Time Series Classification", Computational Statistics \& Data Analysis, c. 50 s. 10, ss. 2668-2684, 2006.

[30] P. D’Urso, E.A. Maharaj, "Autocorrelation-Based Fuzzy Clustering of Time Series", Fuzzy Sets and Systems, c. 160, s. 24, ss. 3565 - 3589, 2009.

[31] E.A. Maharaj, "A Significance Test for Classifying ARMA Models." Journal of Statistical Computation and Simulation, c. 54, s. 4, ss. 305-331, 1996.

[32] E.A. Maharaj, "Clusters of Time Series", Journal of Classification, c. 17, s. 2, ss. 297-314, 2000.

[33] P. Montero, J.A. Vilar, "TSclust: An R package for time series clustering", Journal of Statistical Software c. 62, ss. 1-43, 2014.

[34] O. Kaynar, S. Taştan, ve F. Demirkoparan, "Yapay sinir ağlari ile doğalgaz tüketim tahmini”, Atatürk Üniversitesi Iktisadi ve İdari Bilimler Dergisi, c. 25, 2011.

[35] H. Budak, ve S. Erpolat, "Kredi Riski Tahmininde Yapay Sinir Ağları ve Lojistik Regresyon Analizi Karşılaştırılması", AJIT-e: Online Academic Journal of Information Technology, c. 3, s. 9, 23 $30,2012$.

[36] H. Aygören, H. Saritaş, ve T. Morali, "IMKKB 100 Endeksinin Yapay Sinir Ağları ve Newton Nümerik Arama Modelleri ile Tahmini”, Journal of Alanya Faculty of Business/Alanya Isletme Fakültesi Dergisi, c. 4, s. 1, 2012.

[37] Ö. Yıldız, "Döviz Kuru Tahmininde Yapay Sinir Ağlarının Kullanımı," Yüksek Lisans Tezi, İşletme, Sosyal Bilimler Enstitüsü, Osmangazi Üniversitesi, Eskişehir, Türkiye, 2006. 
[38] Ö. Efe,ve O. Kaynak, Yapay Sinir Ağları ve Uygulamaları, 696. bask1, İstanbul, Türkiye: Boğaziçi Üniversitesi Yayınları, 2000. s. 148.

[39] Ö. Asilkan, ve A. G. S. Irmak, "İkinci El Otomobillerin Gelecekteki Fiyatlarının Yapay Sinir Ağları ile Tahmin Edilmesi”, Süleyman Demirel Üniversitesi İktisadi ve İdari Bilimler Fakültesi Dergisi, c. 14, s. 2, ss. 375-391, 2009.

[40] C. Hamzaçebi, ve F. Kutay, "Yapay sinir ağları ile türkiye elektrik enerjisi tüketiminin 2010 yılına kadar Tahmini”, Gazi Üniversitesi Mühendislik-Mimarlık Fakültesi Dergisi, c. 19, s. 3, 2004.

[41] M. Tolon, ve N.G. Tosunoğlu, "Tüketici Tatmini Verilerinin Analizi: Yapay Sinir Ağlari Ve Regresyon Analizi Karşilaştirmasi”, Gazi Universitesi Iktisadi ve Idari Bilimler Fakultesi Dergisi, c. 10, s. 2, 2008.

[42] H.A. Es, F.Y. Kalender ve C, Hamzaçebi, "Yapay sinir ağlari ile Türkiye net enerji talep tahmini”, Gazi Üniversitesi Mühendislik-Mimarlık Fakültesi Dergisi, c. 29,s. 3, 2014.

[43] A. Akcan, ve C. Kartal, "IMKB Sigorta Endeksini Olusturan Sirketlerin Hisse Senedi Fiyatlarının Yapay Sinir Ağları İle Tahmini”, Muhasebe ve Finansman Dergisi, c. 51, ss. 27-40, 2011.

[44] http://appsso.eurostat.ec.europa.eu/nui/show.do?dataset=htec_si_exp4\&lang=en / 07.09.2020

[45] https://data.worldbank.org/indicator/GB.XPD.RSDV.GD.ZS?locations=TR 20.11.2020

[46] https://data.worldbank.org/indicator/IP.PAT.RESD?locations=TR 20.11.2020

[47] https://www.theglobaleconomy.com/Turkey/trade openness/ 20.11.2020

[48] https://www.theglobaleconomy.com/Turkey/fdi dollars/ 20.11.2020

[49] M. Karaatlı, Ö.C. Helvacıŏlu, N. Ömürbek, ve G. Tokgöz, "Yapay Sinir Ağlari Yöntemi ile Otomobil Satiş Tahmini”, Uluslararası Yönetim İktisat ve Işsletme Dergisi, c. 8, s. 17, 87-100, 2012.

[50] A.K. Kökocak, Ekonomik güç: Bilim ve Teknoloji, Odak Yayın ve Dağıtım, Ankara, 2005, ss. 169.

[51] H. Yaman, ve O. Sungur, "İleri Teknoloji İhtracatı ve Büyüme İlişkisi: OECD Ülkelerine Yönelik Ekonometrik Bir Analiz”, Bolu Abant İzzet Baysal Üniversitesi Sosyal Bilimler Enstitüsü Dergisi, c. 20, s. 1, ss. 63-80, 2020.

[52] N. Topall1, "Doğrudan yabanc1 yatırımlar, ekonomik büyüme ve yüksek teknoloji ihracatı arasında bir nedensellik ilişkisi”, International Journal of Social Sciences and Education Research, c. 1, s. 1, ss. 277-285, 2015.

[53] N. Algan, M. Manga ve M. Tekeoğlu, "Teknolojik Gelişme Göstergeleri ile Ekonomik Büyüme Arasındaki Nedensellik İlişkisi: Türkiye Örneği”, International Conference on Eurasian Economies, İstanbul, Türkiye, 2017, ss. 332-338. 